\title{
ВСТАНОВЛЕННЯ ОСНОВНОГО ЗАКОНУ ЛОГІСТИКИ
}

\author{
Бабайлов В. К., канд. економ. наук, доцент \\ Приходько Д. О., канд. економ. наук, доцент \\ Харківський національний автомобільно-дорожній університет
}

Постановка проблеми. Аналіз літературних джерел свідчить, що досі не встановлена кількісна форма основного закону логістики (ОЗЛ). До того ж й існують тільки три їі приватних закони: 20-80; 10-70; 5-50 [1-10]. Це значно обмежує можливості практики логістики. Тому, встановлення кількісної форми основного закону логістики стає актуальним.

Аналіз останніх досліджень і публікацій. Так, у праці Курганова В. робиться спроба сформулювати приватні закони логістики [11]. Автор також визначає й основний закон логістики як економію сукупних витрат, пов'язаних 3 рухом матеріального потоку [11]. Однак він не визначає кількісну форму основного закону логістики. В праці [12] фактично повторюється вже відоме визначення логістики, як управління матеріальними, інформаційними, фінансовими потоками. Однак в ній теж не ставиться проблеми формулювання кількісної форми основного закону логістики. В праці [13] лише згадується відомий приватний закон Парето - закон 20-80. В джерелі [14] розглядаються навіть кілька основних законів логістики, що на думку авторів $є$ взагалі помилковим. У праці [15] розглядають не закони, а сім правил логістики; але при всій схожести правила і закони - не тотожні поняття. У праці [16] представлені загальні закони логістичного менеджменту та закономірності, що виходять із загальної групи таких законів. Однак відоме, що навпаки закони визначаються із закономірностей [2].

Отже, проведений аналіз показує, що дійсно існує необхідність не тільки встановлення кількісної форми основного закону логістики, але й уточнення розуміння сенсу приватних і основного закон і їх зв'язку.

Невирішені складові загальної проблеми. Практика дослідницької діяльності свідчить, що для встановлення кількісної форми будь-якого основного закону необхідний певний мінімум конкретних приватних законів. Їх узагальнення й дозволяє встановити основний закон у кількісній формі. Однак у логістиці у теперішній час існують всього тільки три приватних закони, причому в дуже обмеженому діапазоні величин причин і результатів. Тому необхідно відкриття ще декількох приватних законів логістики, причому як можливо в найширшому діапазоні вказаних величин. Для рішення цієї складової проблеми автори висказали гіпотезу про можливості встановлення ще двох приватних законів логістики, причому в двох ключових місцях диапазону: у самому його початку та у самому кінці. Саме це дозволить охопити фактично увесь диапазон приватних законів логістики і встановити основний закон логістики. 
Формулювання цілей статті. Метою даного дослідження є встановлення кількісної форми основного закону логістики.

Методики дослідження: огляд літературних джерел, 2С70, BEО, історично-логічний, індукція-дедукція, теорія методу Бабайлова [2].

Виклад основного матеріалу дослідження. Як слідує 3 [1-2] логістика $є$ своєрідна, раціональна організація потоків. Раціональна означає - організована згідно законів логістики 20-80; 10-70; 5-50. Саме раціональна організація потоків забезпечує величезне зменшення витрат щодо найвагоміших в їх ієрархії. Так, наприклад, використання закону 20-80 скорочує витрати на $80 \%$; закону 10 70 - на 90\%; закону 5-50 - на 95\%. Однак й 20\% витрат можуть дозволити собі не всі підприємства. Тому вони можуть застосувати другий закон логістики (1070), який зменшує витрати у два рази (в порівнянні з використанням закону 2080). Й при цьому результат зменшиться лише на $10 \%$.

Але існують організації, які можуть дозволити собі тільки 5\% витрат за рахунок використання третього закону логістики. При цьому, результат зменшиться до 50\%, але він може бути придатним для ефективної логістичної діяльності.

Далі було виявлено, що у практиці логістики виникає проблема визначення величини результату, коли витрати не дорівнюють жодному з трьох розглянутих випадків. Причина цього - відсутність кількісної форми єдиного, основного закону логістики (ОЗЛ).

Для цього необхідно, перш за все, визначити сенс будь-якого основного закону. При вирішенні цього завдання автори використовували важливіші властивості універсальної моделі розробки парадигм [6]. Саме в цій моделі встановлено роль, місце, сутність, зміст основного закону будь-якої сфери діяльності. 3 [6] слідує: місце основного закону - це четвертий елемент основної теорії i другий елемент науки. Причина появи основного закону наслідок узагальнення приватних законів. Роль основного закону - для розробки відповідної парадигми. Сутність основного закону - результат узагальнення приватних законів.

У наступному завданні були визначені причини відсутності ОЗЛ у кількісній формі. Вона зводиться до відсутності реальних передумов встановлення ОЗЛ. Зрозуміло, що нереально встановити основний закон логістики на основі узагальнення тільки трьох законів логістики (20-80; 10-70; 5-50). Вони лише надають інформацію тільки в досить обмеженому діапазоні причин (від 5\% до 20\%) і наслідків (результатів) тільки від 50\% до 80\% (рис. 1). 


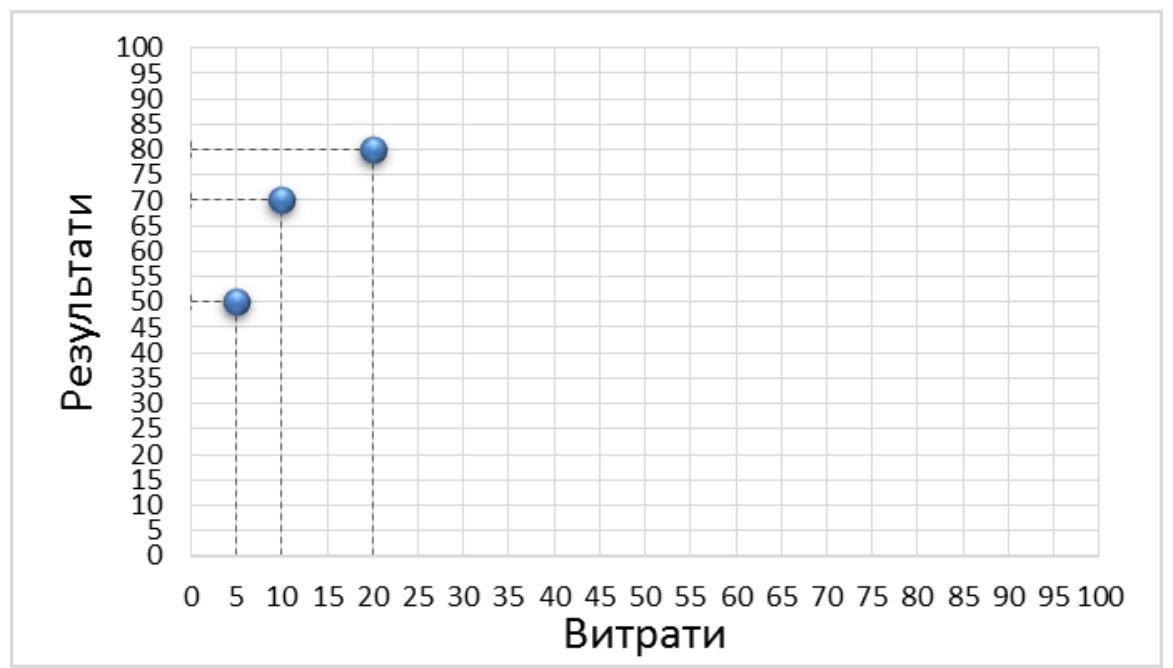

Рис. 1. Обмеженість трьох законів логістики [складено авторами]

Але як себе проявляють кількісно причини і результати за межами даного діапазону досі було невідомо. Зрозуміло, що для узагальнення приватних законів логістики у формі екстраполяції не було можливості - помилка могла бути занадто значною. Для рішення цієї проблеми автори висказали гіпотезу о можливості встановлення ще двох приватних законів логістики, причому в двох ключових місцях диапазону: у самому його початку та й у самому кінці. Так, насправді, можливо стверджувати, що відсутність причин (нуль причин) неминуче веде до відсутності (до нуля) й наслідків (результатів). Це і є новим четвертим приватним законом логістики! Більш за те, не підлягає сумніву, що й на прикінці диапазону 100\% причин обов'язково приведе до 100\% наслідків (результатів). Це ще один - n'ятий приватний закон логістики! Зрозуміло, що наявність вже п'ятьох приватних законів логістики $(20-80 ; 10-70 ; 5-50 ; 0-0 ; 100-$ $100)$, які, до того ж, охоплюють увесь діапазон співвідношення витрат i результатів, надає реальну можливість їх узагальнення шляхом екстраполяції. Це слідує з рис. 2.

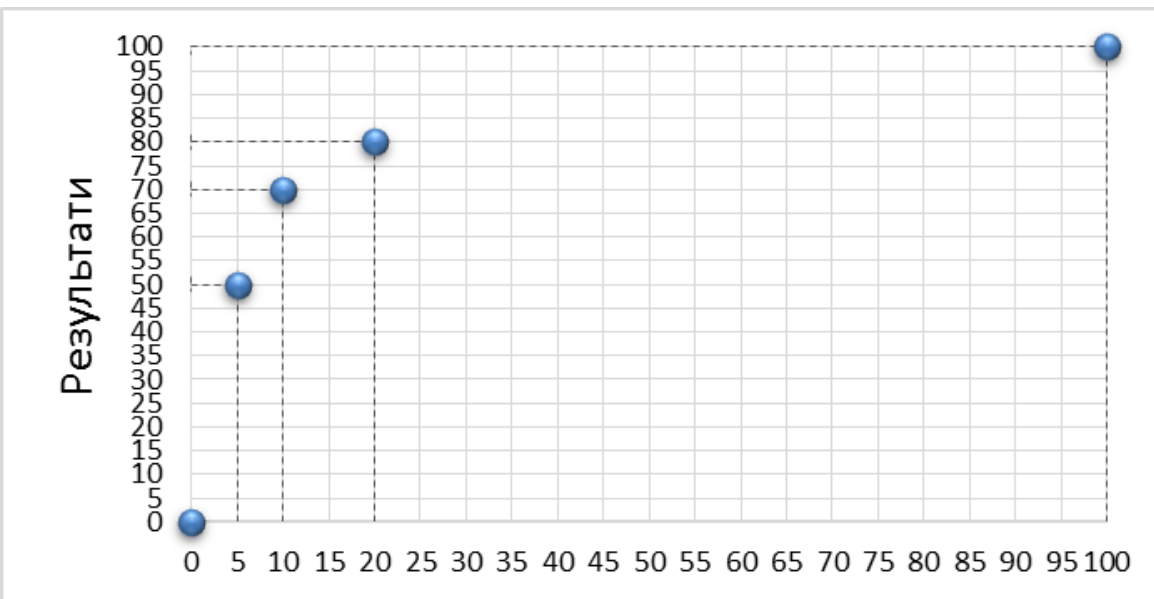

Витрати

\section{Рис. 2. Реальні передумови встановлення основного закону логістики} [складено авторами]

3 рис. 2 наочно слідує реальність проведення кривої залежності величин 
наслідків (результатів) від причин (витрат) через п’ять точок, охоплюючих фактично увесь діапазон причин і наслідків. Тобто, це можливість вирішення шостого завдання дослідження. Крива залежності причин і наслідків і є ОЗЛ. Він представлений на рис. 3.

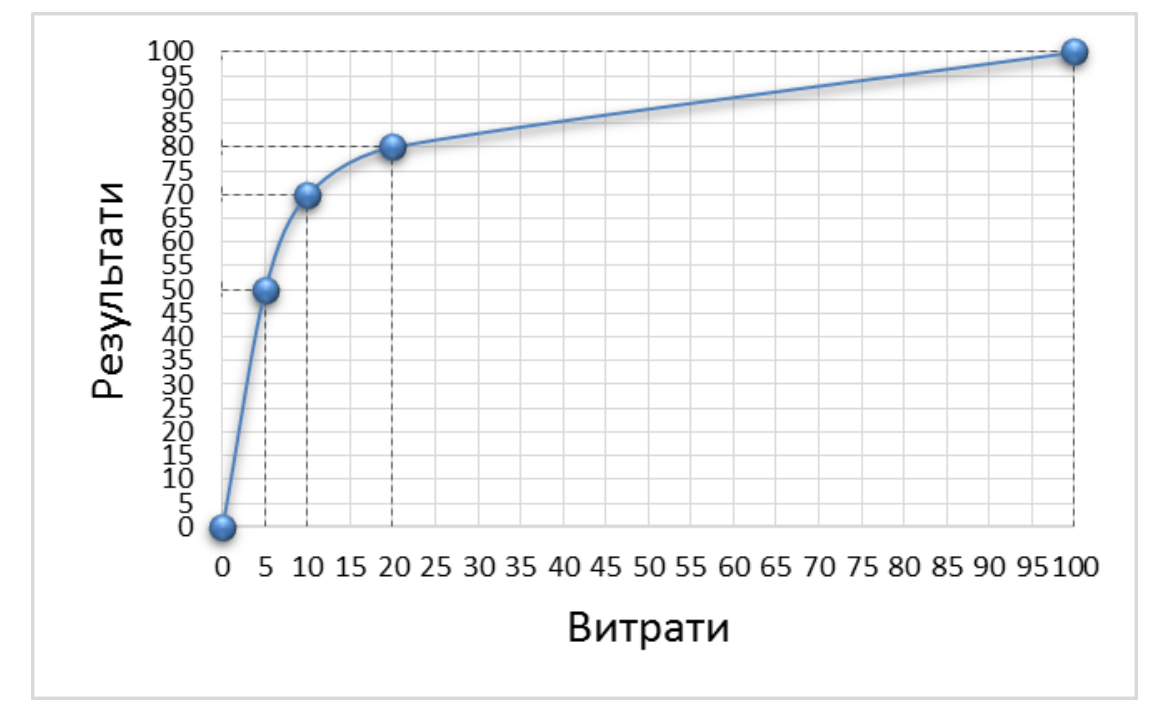

\section{Рис. 3. Основний закон логістики [складено авторами]}

ОЗЛ виконує важливішу роль у практиці логістики. Ї̈̈ визначення - це ще одна проблема даного дослідження. Уся логіка проведеного дослідження приводить до висновку, що саме ОЗЛ становиться критерієм, засобом, методикою практики логістики, засобом визначення можливого, приємного для будь-якого підприємства співвідношення його витрат i результатів. Дане співвідношення не може бути встановлено ніяким іншим засобом. При цьому всі співвідношення витрат і результатів, які опиняться не на кривій «витратирезультати», не відповідають основному закону логістики, і тому не являються логістичними.

Висновки 3 проведеного дослідження. Розробка авторами четвертого i п’ятого приватних законів логістики забезпечила успішне встановлення основного закону логістики в його кількісній формі.

Однак важлива роль ОЗЛ цим не обмежується: його встановлення вперше надає можливість і відкриває шлях до розробки важливіших стратегій логістики, якими є iï парадигми - глобальні стратегії, стратегії поведінки всього людства у сфері логістики в різні історичні відрізки часу (епохи). Але це є проблемою майбутнього окремого дослідження.

\section{Перелік посилань}

1. Бабайлов В. К. Теория метода : монография. Х. : ХНАДУ, 2011. 232 с.

2. Бабайлов В. К. Менеджмент : наука и практика : учебник. Харків: ХНАДУ, 2015. $276 \mathrm{c.}$

3. Бабайлов В. К. Эволюция парадигм экономики. Проблеми $i$ перспективи розвитку підприємниџтва: Збірник наукових праџь харківського національного автомобільно-дорожнього університету. Харків : ХНАДУ, 2014. № 2 (7), том 1. С. 5-8. 
4. Бабайлов В. К. Новая парадигма экономики. Новий колегіум. 2015. № 1. С. 53-57.

5. Бабайлов В. К. Организация модели разработки парадигм экономики. Проблеми $i$ перспективи розвитку підприємництва: Збірник наукових прачь Харківського начіонального автомобільно-дорожнього університету. Харків : ХНАДУ. 2015. о3 (10). том 2. С. 5-9.

6. Бабайлов В. К. Модель разработки парадигм: важнейшие свойства. Новий колегіум. 2016. № 3. С.48-53.

7. Бабайлов В. К. Новая парадигма менеджмента. Проблеми $i$ перспективи розвитку підприємництва: Збірник наукових пращь харківського національного автомобільно-дорожнього університету. 2016. о 3(14). том 1. Х. : ХНАДУ. С. $72-76$.

8. Бабайлов В. К. Новая парадигма методологии. Новий колегіум. 2018. № 1. С.73-77.

9. Бабайлов В. К., Курденко О. В. Инженерия как важнейшая функция управления предприятием. Приазовський економічнии вісник. 2018. № 5 (10). : сайт. URL : http://pev.kpu.zp.ua/vypusk-5-10 (дата звернення: 20.10.2020).

10. Бабайлов В. К., Приходько Д. О. Новая парадигма технологии. Проблеми і перспективи розвитку підприємництва: Збірник наукових прачь Харківського начіонального автомобільно-дорожнього університету. 2018. № 2 (21). C. 15-27. DOI: http://doi.org/10.30977/PPB.2226-8820.2018.21.0.15.

11. Курганов В. Экономические закономерности управления транспортнологистическими процессами. Аналитический журнал по логистике «Ресурсы, Информащия, Снабжение, Конкуренция» (РИСК). 2008. № 3. С. 19-21.

12. Шумаев В. А. Основы логистики : учеб. пособие. М. : Юридический институт МИИТ, 2016. $314 \mathrm{c}$.

13. Левкин Г. Г. Логистика : теория и практика. Ростов н/Д : Феникс, 2009. $221 \mathrm{c}$.

14. Основные законы логистики. Памятка логиста. Новая складская логистика : веб-сайт. URL: http://www.fill2001.narod.ru/ZakonyLogistiki.htm (дата обращения: 12.10.2020).

15. Правила, принципи та функції логістики. Навчальні матеріали онлайн : веб-сайт. URL: https://cutt.ly/9gJL9kQ (дата звернення: 12.10.2020).

16. Пономаренко В. С., Таньков К. М., Лепейко Т. І. Логістичний менеджмент : підручник. Х. : ВД «ІНЖЕК», 2010. 440 с.

\section{References}

1. Babailov, V. K. (2011), Method theory [Teoriya metoda], monografiya, Kharkiv : HNADU, 232 p.

2. Babajlov, V. (2015), Management: Science and Practice [Menedzhment: Nauka i praktika], textbook, Kharkiv : HNADU, 276 p.

3. Babailov, V. (2014), «Evolution of economic paradigms» [«Evolyutsiya paradigm ekonomiki»], Problems and perspectives of entrepreneurship development: Collection of scientific works of Proceedings of Kharkiv National Automobile and Highway University, No. 2 (7), Vol. 1, P. 5-8. 
4. Babailov, V. (2015), «The new paradigm of economics» [«Novaya paradigma ekonomiki»], New collegium, No. 1, P. 53-57.

5. Babaylov, V. (2015), «Organization of a model for the development of economic paradigms» [«Organizatsiya modeli razrabotki paradigm ekonomiki»], Problems and perspectives of entrepreneurship development: Collection of scientific works of Proceedings of Kharkiv National Automobile and Highway University, No. 3 (10), Vol. 2, P. 5-9.

6. Babailov, V. (2016), «Model development of paradigms: the most important properties» [«Model' razrabotki paradigm: vazhnejshie svojstva»], New Collegium, No 3, P. 48-53.

7. Babailov, V. (2016), «The new management paradigm» [«Novaya paradigma menedzhmenta»], Problems and perspectives of entrepreneurship development: Collection of scientific works of Proceedings of Kharkiv National Automobile and Highway University, No 3 (14), Vol. 1, P. 72- 76.

8. Babailov, V. (2018), «The new paradigm of methodology» [«Novaya paradigma metodologii»], New Collegium, No. 1, P. 73-77.

9. Babailov, V., Kurdenko, O. (2018), «Engineering is as the most important function of enterprise management» [«Inzheneriya kak vazhnejshaya funkciya upravleniya predpriyatiem»], Priazovsky Economic Bulletin, No. 5 (10), available at : http://pev.kpu.zp.ua/vypusk-5-10 (last accessed 20.10.2020).

10. Babailov, V., Prykhodko, D. (2018), «The new paradigm of technology» [«Novaya paradigma tehnologii»], Problems and perspectives of entrepreneurship development: Collection of scientific works of Proceedings of Kharkiv National Automobile and Highway University, No 2 (21), P. 15-27. DOI: http://doi.org/10.30977/PPB.2226-8820.2018.21.0.15

11. Kurganov, V. (2008), «Economic patterns of management of transport and logistics processes» [«Ekonomicheskie zakonomernosti upravleniya transportnologisticheskimi protsessami»], Analytical magazine on logistics «Resources, Information, Supply, Competition» (RISC), No 3, P. 19-21.

12. Shumaev, V. A. (2016), Fundamentals of logistics : textbook [Osnovy logistiki : ucheb. posobie], MIIT Law Institute, Moscow, 314 p.

13. Levkin, G. G. (2009), Logistics : theory and practice [Logistika : teoriya i praktika], Feniks, Rostov-on-Don, 221 p.

14. «Basic laws of logistics. Logistician's memo»[«Osnovnye zakony logistiki. Pamyatka logista»], available at http://www.fill2001.narod.ru/ZakonyLogistiki.htm (last accessed 12.10.2020).

15. «Rules, principles and functions of logistics» [«Pravyla, pryntsypy ta funktsii lohistyky»], available at : https://cutt.ly/9gJL9kQ (last accessed 12.10.2020).

16. Ponomarenko, V., Tankov, K., Lepeyko, T. (2010), Logistic management : textbook [Lohistychnyi menedzhment : pidruchnyk], VD «INZHEK», Kharkiv, 440 p. 


\section{РЕФЕРАТИ РЕФЕРАТЫ ABSTRACTS}

УДК 656.07+ 658.8; JEL Classification: N7, R49, L91

Бабайлов В. К., ПриходЬко Д. О. ВСТАНОВЛЕННЯ ОСНОВНОГО ЗАКОНУ ЛОГІСТИКИ

Відсутність основного закону логістики веде до значного обмеження практики структурування та оптимізації потоків у ній. Практика дослідницької діяльності свідчить, що для встановлення кількісної форми будь-якого основного закону необхідний певний мінімум конкретних приватних законів, причому у можливому найширшому діапазоні величин причин (витрат) i наслідків (результатів). Саме узагальнення, екстраполяція вказаної залежності й дозволить встановити основний закон логістики у кількісній формі. Але існування в даний час тільки трьох приватних законів логістики (20-80; 10-70; 5-50) недостатньо для цього. Для рішення цієї проблеми автори висказали гіпотезу о можливості встановлення ще двох приватних законів логістики, причому в двох ключових місцях диапазону: у самому його початку та у самому кінці. Саме це дозволить охопити фактично увесь диапазон приватних законів логістики і встановити основний закон логістики у кількісній формі. Метою даного дослідження $\epsilon$ встановлення кількісної форми основного закону логістики. Методики дослідження: огляд літературних джерел, 2С70, ВЕО, історично-логічний, індукція-дедукція, теорія методу Бабайлова. Результати: відкриті два нові (четвертий і п’ятий) приватні закони логістики; на основі трьох існуючих і двох нових приватних законів логістики був встановлений основний закон логістики в його кількісній формі. Наукова новизна: вперше встановлені два нових приватних закони логістики і на цій основі встановлено основний закон логістики в його кількісній формі. Практична значущість: основний закон логістики у кількісній формі є єдиною методикою у практиці логістики, яка забезпечить раціональну (логістичну) організацію потоків для будь-яких співвідношень величин витрат і результатів.

Ключові слова: логістика; приватні закони; основний закон; потоки; витрати; результати; організація; створення; структурування; оптимізація потоків.

УДК 656.07+ 658.8; JEL Classification: N7, R49, L91

Бабайлов В. К., ПриходЬко Д. А. УСТАНОВЛЕНИЕ ОСНОВНОГО ЗАКОНА ЛОГИСТИКИ

Отсутствие основного закона логистики ведет к значительному ограничению практики структурирования и оптимизации потоков в ней. Практика исследовательской деятельности свидетельствует о том, что для установления количественной формы любого основного закона необходим определенный минимум конкретных частных законов, причем в максимально широком возможном диапазоне величин причин (расходов) и последствий (результатов). Именно обобщение, экстраполяция указанной зависимости и позволит установить основной закон логистики в количественной форме. Но существование в настоящее время только трех частных законов логистики (20- 
80; 10-70; 5-50) недостаточно для этого. Для решения этой проблемы авторы высказали гипотезу о возможности установления еще двух частных законов логистики, причем в двух ключевых местах диапазона: в самом его начале и в самом конце. Именно это позволит охватить практически весь диапазон частных законов логистики и установить основной закон логистики в количественной форме. Целью данного исследования является установление количественной формы основного закона логистики. Методики исследования: обзор литературных источников, 2С70, ВЕО, исторически-логический, индукция-дедукция, теория метода Бабайлова. Результаты: открыты два новых (четвертый и пятый) частные законы логистики; на основе трех существующих и двух новых частных законов логистики был установлен основной закон логистики в его количественной форме. Научная новизна: впервые установлены два новых частных закона логистики и на этой основе установлено основной закон логистики в его количественной форме. Практическая значимость: основным законом логистики в количественной форме является единая методика в практике логистики, которая обеспечит рациональную (логистическую) организацию потоков для любых соотношений величин затрат и результатов.

Ключевые слова: логистика; частные законы; основной закон; потоки; расходы; результаты; организация; создание; структурирование; оптимизация потоков.

\section{UDC 656.07+ 658.8; JEL Classification: N7, R49, L91 \\ Babailov V., Prykhodko D. ESTABLISHMENT OF THE BASIC LAW OF LOGISTICS}

The absence of the basic law of logistics leads to a significant limitation of the practice of structuring and optimizing flows in it. The practice of research shows that to establish the quantitative form of any basic law requires a certain minimum of specific private laws, and besides in the widest possible range of causes (costs) and consequences (results). It is the generalization, extrapolation of this dependence that will establish the basic law of logistics in quantitative form. But the current existence of only three private laws of logistics $(20-80 ; 10-70 ; 5-50)$ is not enough for this. To solve this problem, the authors hypothesized the possibility of establishing two more private laws of logistics, and in two key places in the range: at the very beginning and at the very end. This will cover virtually the entire range of private laws of logistics and establish the basic law of logistics in quantitative form. The purpose of this study is to establish the quantitative form of the basic law of logistics. Research methods: review of literature sources, 2C70, VEO, historical-logical, induction-deduction, theory of Babaylov's method. Results: two new (fourth and fifth) private laws of logistics were discovered; on the basis of three existing and two new private laws of logistics, the basic law of logistics was established in its quantitative form. Scientific novelty: for the first time two new private laws of logistics were established and on this basis the basic law of logistics in its quantitative form was established. Practical significance: the basic law of logistics in quantitative form is the only technique in 
the practice of logistics, which will provide a rational (logistical) organization of flows for any ratio of costs and results.

Keywords: logistics; private laws; basic law; flows; costs; results; organization; creation; structuring; flow optimization.

\section{Відомості про авторів / Сведения об авторах / About the Authors}

Бабайлов Василь Кузьмич - кандидат економічних наук, Харківський національний автомобільно-дорожній університет, доцент кафедри економіки i підприємництва, м. Харків, Україна; e-mail: super_super-kod@ukr.net.

Бабайлов Василий Кузьмич - кандидат экономических наук, Харьковский национальный автомобильно-дорожный университет, доцент кафедры экономики и предпринимательства, г. Харьков, Украина.

Babailov Vasil - PhD, Kharkiv National Automobile and Highway University, Associate professor of the Department of Economics and Entrepreneurship, Kharkiv, Ukraine.

Приходько Дар'я Олександрівна - кандидат економічних наук, доцент, Харківський національний автомобільно-дорожній університет, доцент кафедри економіки і підприємництва, м. Харків, Україна; e-mail: zajada@gmail.com; ORCID: https://orcid.org/0000-0003-3925-4828. Моб. 066-97-44-135.

Приходько Дарья Александровна - кандидат экономических наук, доцент, Харьковский национальный автомобильно-дорожный университет, доцент кафедры экономики и предпринимательства, г. Харьков, Украина.

Prykhodko Daria - PhD in Economics, Associate Professor, Kharkiv National Automobile and Highway University, Associate Professor of the Department of Economics and Entrepreneurship, Kharkiv, Ukraine. 